\title{
The Fatty Acids Present in the Rumen of Lambs Fed on a Flaked Maize Ration
}

\author{
By A. T. PHILLIPSON \\ Rowett Research Institute, Bucksburn, Aberdeenshire
}

(Received I6 fuly 1951)

The cobalt-deficient diet introduced by Stewart (r947) contains flaked maize as this foodstuff contains very little cobalt. Experiments in which this ration was used have already been described (Phillipson \& Mitchell, I952), and examination of the rumen contents of some of the lambs involved revealed an unusual bacteriological picture (Masson, 1950, 195I), for the protozoa had disappeared from the rumen and the usual population of iodophilic cocci seen in sheep fed on diets containing starch had been largely displaced by rod-like sporulating organisms later identified as Clostridium butyricum. In addition, lactic acid-producing bacteria (lactobacilli) were isolated. These observations were most marked in those lambs receiving cobalt, for they ate more of the flaked maize mixture. Lambs receiving no supplementary cobalt did not show this picture to such a marked extent.

Masson's observations suggested that the acids formed as a result of fermentation would not be present in their usual proportions, and for this reason chromatographic separation of the steam-volatile acids was undertaken and the results are presented in this paper.

\section{METHODS}

Management of lambs. The eight lambs used in the experiments recorded by Phillipson \& Mitchell (1952) were approximately 8 months old when they were placed on the experimental ration and were all fitted with a rumen cannula in the usual way. They were fed at $8 \mathrm{a} . \mathrm{m}$. with the flaked maize mixture and at $4 \mathrm{p} . \mathrm{m}$. with $15^{\circ} \mathrm{g}$ hay. The flaked maize mixture consisted of ten parts flaked maize and one part maizegluten feed. To this were added $12 \mathrm{~g}$ steamed bone-flour daily. This ration was allowed ad lib. up to a maximum of $\mathrm{I} \mathrm{kg}$ daily. Lambs nos. 999 and 1012 received 0.I mg cobalt by mouth daily in the form of cobalt sulphate. Lambs nos. 993 and 997 received cobalt by abomasum and were fitted with abomasal cannulas for this purpose; lambs nos. 995 and roro received cobalt into the duodenum through duodenal cannulas, whereas lambs nos. 994 and Ior 4 received no supplementary cobalt. Details of the method of administration of cobalt into the abomasum and duodenum have been given by Phillipson \& Mitchell (1952).

Chemical. Rumen liquor was withdrawn in the usual way and strained through muslin. Total volatile fatty acids were estimated by steam distillation and the distillates titrated with $0 \cdot 05-\mathrm{N}$ sodium hydroxide under carbon dioxide-free conditions. The purification and extraction of the acids for chromatographic separation were as described by Elsden (1946). Buffered columns were used to separate the acids as 
described by Moyle, Baldwin \& Scarisbrick (1948). Column I was used which separates acetic, propionic and butyric acids quantitatively. Acids higher in series than butyric pass through rapidly without separating and can be collected and titrated as one fraction. They were closely followed by the wave of butyric acid, and sometimes a complete separation of butyric from the higher acids was not obtained. About $0.25-0.5 \mathrm{~m}$-equiv. of acids in $5 \mathrm{ml}$. chloroform-butanol solvent were placed on the column.

Lactic acid was determined according to the methods of Friedemann \& Graeser (1933); glucose, by the copper-reduction method of Somogyi (r945) and $\mathrm{pH}$ by the use of a glass electrode.

\section{RESULTS}

Preliminary investigations in which total volatile fatty acids only were determined showed that the concentration of these acids was rather lower than would be expected from the high starch content of the ration. Concentrations of volatile fatty acids of $1.41-3.65 \mathrm{~m}$-equiv./100 $\mathrm{ml}$. were found in the morning $\mathrm{I} \mathrm{h}$ after feeding and the highest values found ranged from 6.76 to $1 \mathrm{r} \cdot 72 \mathrm{~m}$-equiv./100 $\mathrm{ml}$. Hourly samples were drawn from each of the eight lambs from 9 a.m. to 5 p.m. and the concentration exceeded $10 \mathrm{~m}$-equiv./100 ml. in only two samples.

It was clear from the analysis of these samples that a partly volatile acid was present since the titre of the distillates did not return to the blank value by the third $50 \mathrm{ml}$. portion. Lactic acid is known to occur in the rumen under certain circumstances, and direct estimations revealed the presence of high concentrations in two lambs, nos. 997 and 999, and of appreciable concentrations in lambs nos. 995 and ror 4 , as is illustrated in Fig. 1 .

Further investigations on the remaining four lambs, nos. 1012, 993, 1010 and 994, showed that high concentrations, $7.0 \mathrm{~m}$-equiv./100 ml., were reached in two of them, nos. I012 and roro, a concentration exceeding $0.50 \mathrm{~m}$-equiv./100 ml. was attained in no. 993 and traces were present in one lamb, no. 994, which was a cobalt-deficient animal with a correspondingly poor appetite. The $\mathrm{pH}$ of the rumen liquor, given in Table I, was exceptionally low.

One of the lambs, no. 993, was selected in order to examine the composition of the steam-volatile acids. Two samples were taken, one at 12 noon and one at 5 p.m., so

Table $\mathrm{r} . \mathrm{pH}$ and concentration of lactic acid at different times of the day in the rumen liquor of lambs fed on a ration containing a high proportion of flaked maize

Lamb no.

\begin{tabular}{|c|c|c|c|c|c|c|c|c|}
\hline & \multicolumn{2}{|c|}{1012} & \multicolumn{2}{|c|}{993} & \multicolumn{2}{|c|}{1010} & \multicolumn{2}{|c|}{994} \\
\hline Time & $\mathrm{pH}$ & $\begin{array}{l}\text { Lactic acid } \\
\text { (m-equiv./ } \\
\text { 100 ml.) }\end{array}$ & $\mathrm{pH}$ & $\begin{array}{c}\text { Lactic acid } \\
\text { (m-equiv./ } \\
\text { roo ml.) }\end{array}$ & pH & $\begin{array}{c}\text { Lactic acid } \\
\text { (m-equiv./ } \\
100 \mathrm{ml} \text { ) }\end{array}$ & pH & $\begin{array}{c}\text { Lactic acid } \\
\text { (m-equiv.) } \\
100 \mathrm{ml} . \text { ) }\end{array}$ \\
\hline $\begin{array}{l}9 \text { a.m. } \\
12 \text { noon }\end{array}$ & $\begin{array}{l}5 \cdot 6 \\
4 \cdot 8\end{array}$ & $\begin{array}{l}0.37 \\
2.65\end{array}$ & $\begin{array}{l}4.5 \\
4.5\end{array}$ & $\begin{array}{l}0.40 \\
4.07\end{array}$ & $\begin{array}{l}5 \cdot 1 \\
4 \cdot 6\end{array}$ & $\begin{array}{l}0.15 \\
6.75\end{array}$ & $\begin{array}{l}6 \cdot 1 \\
6 \cdot 6\end{array}$ & $\begin{array}{l}0.17 \\
0.30\end{array}$ \\
\hline 3 p.m. & $4 \cdot 6$ & $7 \cdot 25$ & 4.3 & $5 \cdot 25$ & $4 \cdot 5$ & 7.00 & 6.3 & 0.60 \\
\hline 6 p.m. & 47 & $4 \cdot 25$ & $4^{\circ} 9$ & $2 \cdot 75$ & $4 \cdot 6$ & $4 \cdot 12$ & $6 \cdot 1$ & 0.22 \\
\hline Io p.m. & $5 \cdot 6$ & $2 \cdot 12$ & $5 \cdot 7$ & 0.22 & $5^{\cdot 2}$ & $x \cdot 74$ & $6 \cdot 9$ & 0.16 \\
\hline & & & & & & & & $13-2$ \\
\hline
\end{tabular}


that the peak of fermentation and a later stage could be compared. The results are given in Table 2 and show that a high proportion of propionic acid was present, particularly at midday when it exceeded that of acetic acid.

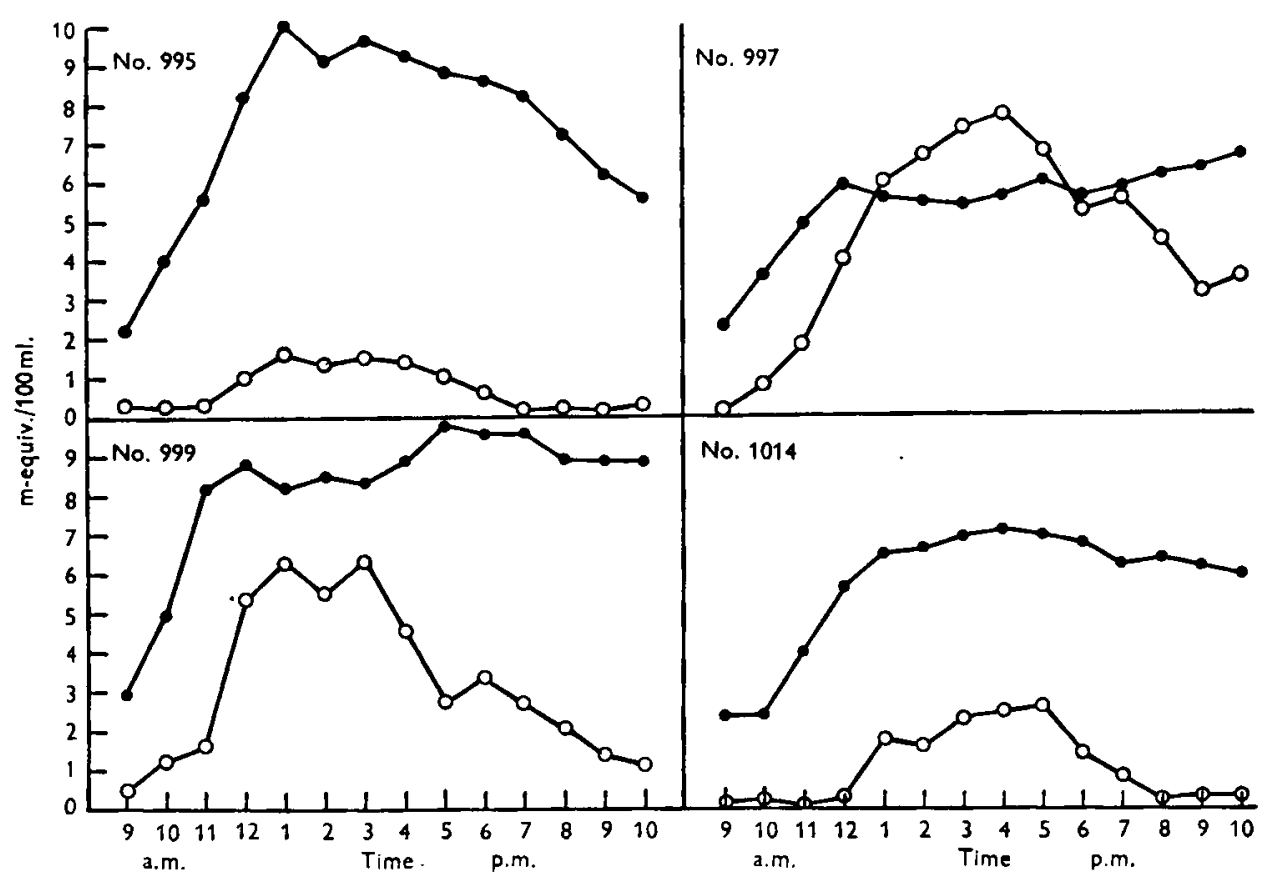

Fig. 1. Changes found in the total volatile acid and lactic acid concentrations in rumen liquor from four lambs throughout a $12 \mathrm{~h}$ period. The lambs received the maize mixture at 8 a.m. and hay at 4 p.m. $\longrightarrow$, total volatile acids; $\mathrm{O}-\mathrm{O}$, lactic acid.

Table 2. Concentrations of fatty acids in the rumen of lamb no. 993 fed on the maize ration

\begin{tabular}{|c|c|c|c|c|}
\hline \multirow[b]{2}{*}{ Acid } & \multicolumn{2}{|c|}{ I2 noon } & \multicolumn{2}{|c|}{5 p.m. } \\
\hline & $\begin{array}{l}\text { m-equiv./ } \\
\text { 100 ml. }\end{array}$ & $\begin{array}{c}\text { Percentage } \\
\text { of total }\end{array}$ & $\begin{array}{l}\text { m-equiv./ } \\
\text { I00 ml. }\end{array}$ & $\begin{array}{c}\text { Percentage } \\
\text { of total }\end{array}$ \\
\hline Acetic & $1 \cdot 50$ & 37 & $2 \cdot I I$ & 45 \\
\hline Propionic & $1 \cdot 95$ & 48 & $1 \cdot 83$ & 39 \\
\hline Butyric & 0.49 & 12 & 0.56 & 12 \\
\hline Higher acids & 0.12 & 3 & O.19 & 4 \\
\hline
\end{tabular}

The low proportion of butyric acid was surprising on account of the presence of considerable numbers of $\mathrm{Cl}$. butyricum, an organism known to produce acetic and butyric acids in vitro under certain conditions. In order to confirm the low proportion present in the rumen, further samples were withdrawn at $2.30 \mathrm{p} . \mathrm{m}$. from each of the eight lambs, and the results from them were similar except that the proportion of propionic acid, although still considerable, was not so marked as in the previous samples shown in Table 2. The proportion of butyric acid, however, as shown in Table 3, was small in all lambs except no. ror4. These results left no doubt that 
the acetic: propionic ratio was narrower than is usually found in sheep fed on other rations.

The peculiar results found for lambs nos. 1014 and 994 may not have been due to the inadequate cobalt in the ration; neither lamb ate as much of the flaked maize mixture as the lambs that received cobalt, and this in itself was likely to influence the result. The amount of food consumed by each lamb on the day the samples were withdrawn is given in Table 3 .

The food intake was consistent for any particular period, and although the appetite of the deficient lambs decreased with time, the decrease was slow. Weight gains by lambs receiving adequate cobalt ranged from $28 \frac{1}{2}$ to $37 \mathrm{lb}$. over a 20 -week period (Phillipson \& Mitchell, r952).

Two lambs, nos. IOI 2 and 1014, were selected for further work. Lamb no. 10I4 was given $0.005 \mathrm{mg}$ cobalt by mouth daily in order to prevent acute symptoms of deficiency setting in, since her companion, no. 994, was in poor condition and later died. The ration given to no. 1012 was reduced so as to equal as far as possible that of no. Ior4. A comparison of the concentrations of lactic and volatile acids in these two lambs was made I month later and little difference between them was found. The lactic-acid concentrations in no. Ior 2 were now very small although still greater than in no. 1014. The data are given in Table 4.

A significant difference, however, was found after chromatographic separation of the steam-volatile acids, the proportion of propionic acid being greater in no. IOI2 than in no. 1014. The proportion in both lambs was now less than previously, although the food eaten by no. ror 4 had not changed in quantity. There was a large difference between the weights of the two lambs, however; no. ror 2 weighed $73.5 \mathrm{lb}$. and no. I014, $53 \mathrm{lb}$. at this time. Forty-two days later further samples were withdrawn from these lambs and the volatile acids again partitioned. The results of both sets of analyses are given in Table 4 .

In the earlier analyses an increase followed by a decrease in the proportion of propionic acid was found in lamb no. IOI2. The second set of analyses, although less complete, shows the same increase in both lambs. The proportions of propionic acid in lamb no. IOI 2 were, however, less in the second set than in the first, and the difference between the two lambs seemed to be disappearing.

The result of introducing an aqueous solution of $100 \mathrm{~g}$ glucose into the rumens of these lambs was investigated. No food was given in the morning after the first sample was drawn, and a sample was drawn before, and at intervals after, the introduction of glucose into the rumen. Glucose disappeared rapidly from the rumens of both lambs, although the concentration attained in no. 1012 was far greater than that found in no. IOI4. The fermentation appeared to pass rapidly to the lactic-acid stage and slowly to the volatile-acid stage, as can be seen from Fig. 2. This was more marked in no. Ior 2 than in no. I014, for the concentration of lactate formed in this lamb was greater and fermentation more prolonged than in no. 1014, whereas a change in the fatty acids was not seen till $4 \mathrm{~h}$ after the administration of glucose. The increase in propionic acid in no. IOI4, however, although more rapid and more pronounced, was insignificant compared with the concentration of lactate formed and disappearing. 
要

趂

ㅇำ

s

है

$$
\text { 焉 }
$$

จ

$-\frac{1}{4}$

政

焉

क्ष

ริ)

$\approx$



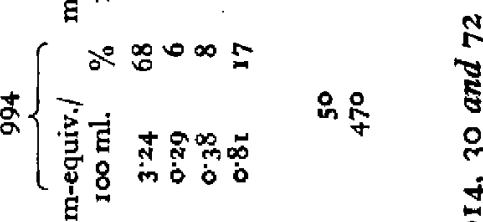

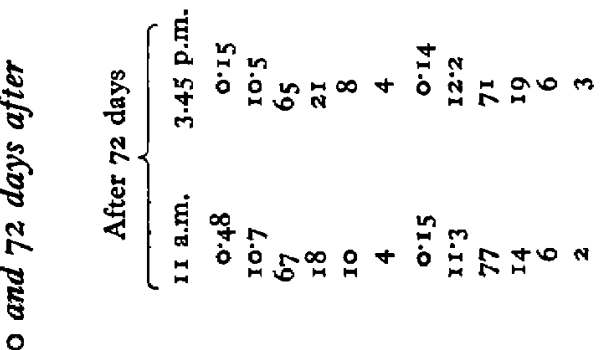

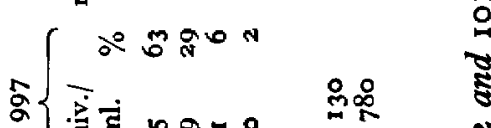

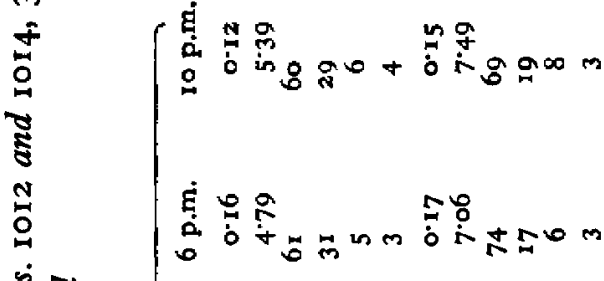

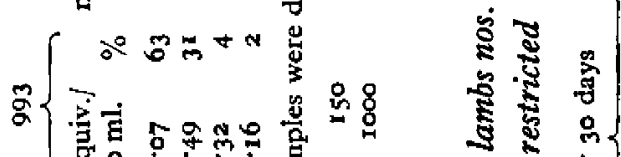

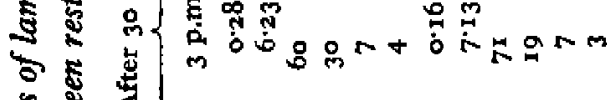

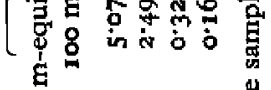

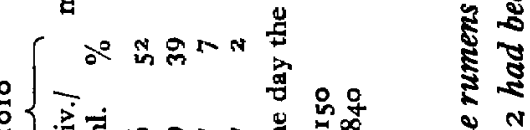

.

ชู

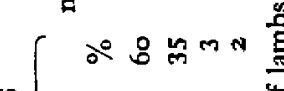

焉密

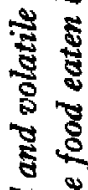

ช 노

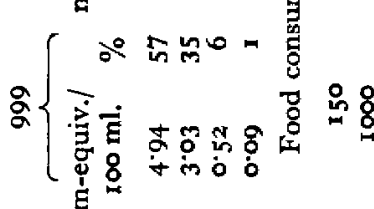

范

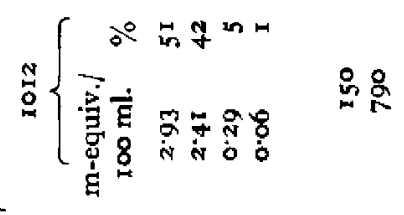

댕ำ

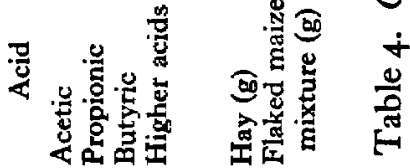

통ํํำำ

$\stackrel{+}{\stackrel{5}{0}}$

$\dot{m}$

造 
A further experiment in which lactate was introduced into the rumens of the two lambs confirmed the results obtained with glucose. The concentration of lactate found after dosing was greater in no. ror2 than in no. ror 4 and the rate at which it disappeared was slower.

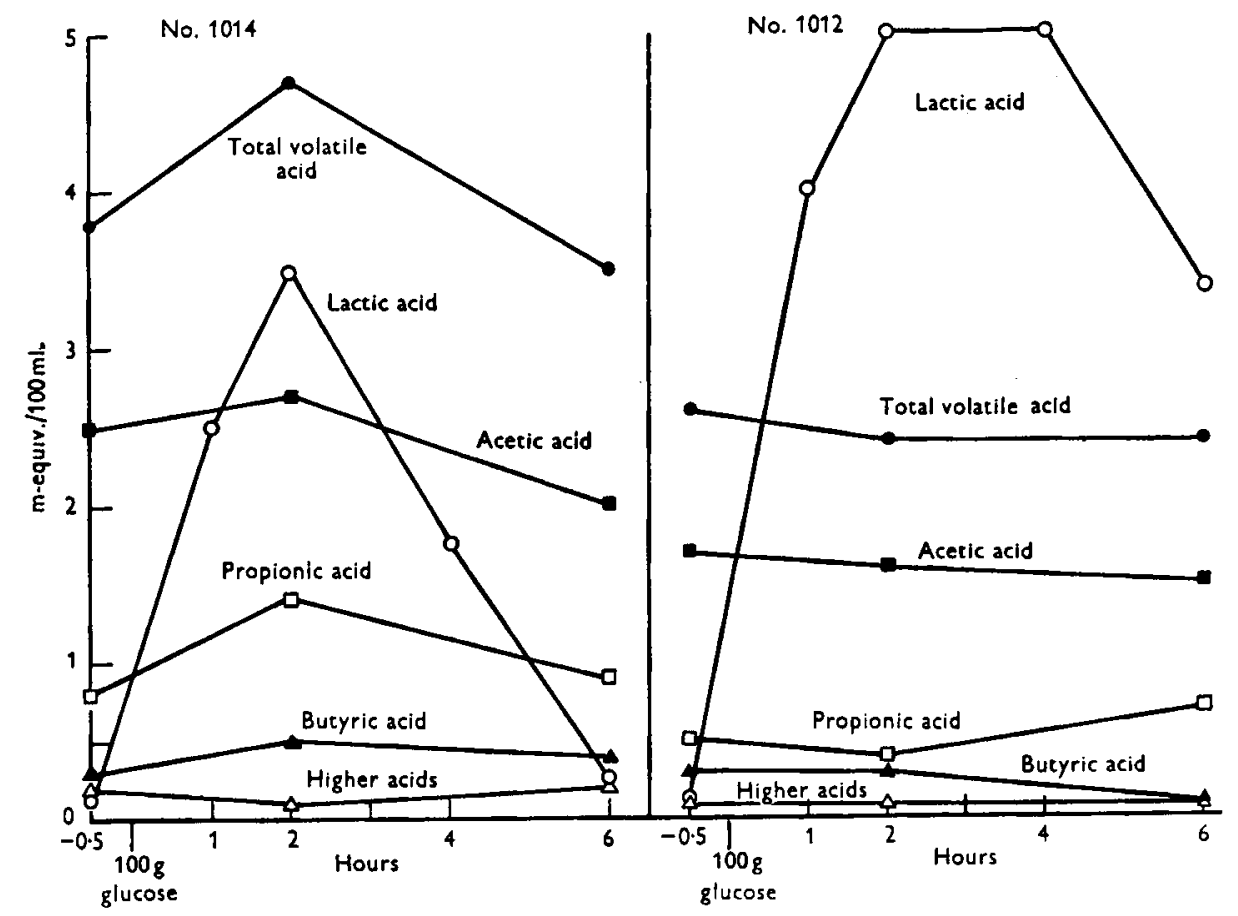

Fig. 2. Changes observed in the concentrations of acetic, propionic, butyric and higher fatty acids and lactic acid after the administration of $100 \mathrm{~g}$ glucose in solution into the rumens of two lambs.

\section{DISCUSSION}

The two most striking features of these analyses are the high concentrations of lactic acid in the lambs on the full flaked maize ration and the high proportion of the total volatile fatty acid represented by propionic acid. Turner \& Hodgetts (quoted by Masson, 195I) and Reid (personal communication) have found high concentrations of lactic acid in the rumens of sheep receiving food containing wheat, and Reid and his colleagues have also shown that the proportion of propionic acid to acetic acid was unusually high. The present observations in which flaked maize was the source of starch agree well, therefore, with those of the Australian workers. This is a different picture from that usually found in the rumen, for under most circumstances little, if any, lactic acid is present (Phillipson, 1942), and propionic acid represents less than $20 \%$ of the total fatty acid (Elsden, 1945; Schambye \& Phillipson, 1949; Kiddle, Marshall \& Phillipson, r95I), except when rations of 'wheaten chaff' (wheat cut immediately after the flowering stage and dried) and lucerne hay are fed, when values as high as $27 \%$ have been recorded (Gray \& Pilgrim, 1951). Lactic acid has previously been found in quantity only when mangolds were fed or when glucose was introduced into the rumen (Phillipson \& McAnally, 1942; Elsden, 1945). 
In spite of the high lactate concentrations, those of total volatile fatty acids were lower than is usual in fully fed sheep. The total volatile fatty-acid concentration in the rumen of sheep in this Institute fed the usual indoor rations or maintained only on hay varies usually between the levels of 60 and $130 \mathrm{mmol}$. In these lambs the range was lower and on only two occasions exceeded $100 \mathrm{mmol}$. Lactate is unstable in the rumen of normally fed sheep, and on account of this seldom accumulates in any quantity; if it does, as for an instance in sheep eating mangolds or after the introduction of glucose into the rumen, the concentration decreases nearly as rapidly as it had previously risen.

Elsden (1945) has isolated propionic-acid bacteria from the rumen of sheep, and Johns ( $195 \mathrm{I} a-c)$ has studied in detail the fermentation of lactate by Veillonella gazogenes, which he found to be numerous in the rumen. Johns found that the ratio of acetic acid to propionic acid was influenced by the carbon-dioxide tension in the medium, and suggested a scheme for the fermentation of lactate which terminated by the decarboxylation of succinate to propionic acid and carbon dioxide. Elsden \& Sypesteyn (1950) have also observed this reaction, using washed-cell suspensions of rumen bacteria.

The fermentation of starch in the rumen of these lambs appears to have taken place in at least two stages in a manner postulated by Elsden (1945); the first stage leading to the formation of lactic acid and the second being the further fermentation of lactic acid with production of volatile fatty acids of which propionic acid is prominent. Cl. butyricum in pure culture is known to form acetic and butyric acids in an acid medium; it was surprising, therefore, that such small quantities of butyric acid were present in the rumen. In media in which the $\mathrm{pH}$ is buffered between 6 and 7 the presence of bicarbonate encourages lactic-acid formation by this organism, although it is possible that the important factor here is the presence of bicarbonate rather than the stabilization of the $\mathrm{pH}$. Cl. butyricum, therefore, may be responsible for some of the lactic acid produced. The presence of lactobacilli, however, provides an additional reason for the large concentrations of lactate present. Most of these organisms ferment only sugars, but according to Sherman (1937) Streptococcus bovis, normally present in the alimentary tract of the ox, hydrolyses starch and produces lactic acid from glucose and a variety of other sugars. Both these organisms, therefore, could be concerned with the production of the high concentrations of lactic acid observed.

The introduction of glucose in the rumens of lambs nos. 1012 and 1014 caused the immediate production of high concentrations of lactic acid, but the changes in the concentrations of acetic and propionic acids were insignificant in comparison. It appears, therefore, that the first stage of lactic-acid fermentation proceeded at a greater rate than the subsequent fermentation of lactate to acetic and propionic acids, and whereas the high proportion of propionic acid is positive evidence of lactate fermentation as studied by Elsden (1945) and Johns (1951 $a$ ), the speed of this fermentation appeared to be slower than that of the initial starch fermentation.

The low $\mathrm{pH}$ found in the rumen of these lambs favours rapid absorption of shortchain fatty acids and according to Danielli, Hitchcock, Marshall \& Phillipson (r945) the longer the hydrocarbon chain the more rapid this absorption, so that the low 
concentration of total volatile acids may be due partly to the rapid absorption of butyric, and to a less extent of propionic, acid. Even so, the rapid production of any acid in the rumen is associated with an increase in its concentration, and I have found no evidence of a significant increase in concentration of butyric acid in these experiments; indeed the reverse occurred in lamb no. 1012 in the series of analyses given in Table 4 .

These investigations were undertaken in order to determine whether any differences could be detected between the lambs receiving cobalt and those receiving no supplementary cobalt. Reference to Table 3 shows that there was a marked difference in the fatty-acid picture of no. 994 and the propionic acid present in no. 1014 was proportionately less and butyric acid proportionately greater than in the other lambs. These differences, however, may have been due to the differences in the quantity of food rather than to inadequate cobalt. The striking feature of the analyses made on no. 994 is not only the exceptionally low proportion of propionic acid but the exceptionally high proportion of higher acids, which suggests rapid deamination of protein according to Shazly \& Synge (1950). This lamb ultimately died. The subsequent comparison of lambs nos. 1012 and 1014 failed to reveal any real difference between them, and no conclusions can be drawn concerning the influence of cobalt in the results obtained.

\section{SUMMARY}

I. Lambs fed on a ration of $15 \circ \mathrm{g}$ hay and a mixture of flaked maize and maizegluten feed in the proportions of $10: I$ to a maximum of $I \mathrm{~kg}$ daily, developed unusually acid conditions in the rumen although their weight gains were adequate if supplemented by cobalt.

2. Lactic acid appeared in the rumen in greater concentration than is usually found, and values exceeding $7 \mathrm{~m}$-equiv./100 ml. were observed. The concentration of acetic acid was lower, and the concentration of propionic acid greater, than is usual, so that the ratio acetic : propionic acid was unusually narrow.

3. Fermentation of glucose in the rumen of two lambs resulted in the rapid accumulation of lactic acid. The subsequent changes in the concentrations of acetic and propionic acids were insignificant in comparison.

\section{REFERENCES}

Danielli, J. F., Hitchcock, M. W. S., Marshall, R. A. \& Phillipson, A. T. (1945). Y. exp. Biol. $22,75$.

Elsden, S. R. (1945). F. exp. Biol. 22, 51 .

Elsden, S. R. (1946), Biochem. F. 40, 252.

Elsden, S. R. \& Sypesteyn, A. K. (1950). F. gen. Microbiol. 4, xi.

Friedemann, T. E. \& Graeser, J. B. (I933). F. biol. Chem. roo, 29 r.

Gray, F. V. \& Pilgrim, F. (I95I). F. exp. Biol. 28, 83.

Johns, A. T. (1951 a). Ұ. gen Microbiol. 5, 317.

Johns, A. T. (195 I b). F. gen. Microbiol. 5, 326.

Johns, A. T. (195 I c). F. gen. Microbiol. 5, 337.

Kiddle, P., Marshall, R. A. \& Phillipson, A. T. (195I). F. Physiol. Ir3, 207.

Masson, M. (1950). Brit. $¥$. Nutrit. 4, viii.

Masson, M. J. (195I). Research, 4, 73.

Moyle, V., Baldwin, E. \& Scarisbrick, R. (1948). Biochem. F. 43, 308.

Phillipson, A. T. (1942). F. exp. Biol. 19, 186.

Phillipson, A. T. \& McAnally, R. A. (1942). F. exp. Biol. r9, r99. 
Phillipson, A. T. \& Mitchell, R. L. (1952). Brit. F. Nutrit., 6, 776.

Schambye, P. \& Phillipson, A. T. (1949). Nature, Lond., 164, 1094.

Shazly, K. \& Synge, R. L. M. (1950). Int. Congr. Physiol. xvirr. Copenhagen, p. 445.

Sherman, J. M. (1937). Bact. Rev. r, 57.

Somogyi, M. (1945). F. biol. Chem. 160, 69.

Stewart, J. (1947). Biochem. F. 4I, xlii.

\title{
Some Observations on the Diet of Jamaican Children, with Particular Reference to Liver Disease
}

\author{
By KATERINA RHODES (Macy Foundation Research Fellow) \\ Department of Pathology, University College Hospital of the West Indies, Mona, \\ St Andrew, Famaica
}

(Received I 8 Fuly 1951)

The object of this communication is to describe the inadequate diet of Jamaican children suffering from liver disease.

\section{EXPERIMENTAL}

Clinical material studied. During the past 15 months, $\mathrm{I}_{5} 5$ cases of liver disease have been investigated in this Department by Hill (195I) and Hill \& Rhodes (195I). Ninety liver biopsies were performed on fifty-eight of the cases by the needle technique and, in addition, ten post-mortem specimens were examined. Though the majority of these patients looked chubby and well nourished, all had an enlarged liver (P1. I) and some had enlargement of the spleen with ascites and, occasionally, oedema of the legs. If ascites was present it refilled rapidly after paracentesis abdominis. None of the patients had malaria or any other acute or chronic infection or infestation with parasites.

The liver sections showed a continuously developing histological picture which we have termed 'serous hepatosis'; this picture, commencing with a serous exudation within the perisinusoidal spaces of Disse, passed on to the laying down of an eosinophilic coagulum which subsequently became fibrosed to give a final appearance of what is usually known as cirrhosis (Hill, 195I). Fatty metamorphosis of the liver as described by Waterlow (1948) was found only in five cases; these however showed, in addition, the fundamental pathological lesions described above. Approximately $30 \%$ of the total number of children, clinically and histologically, had cirrhosis of the liver with fibrosis, hyperplasia and distortion of lobular architecture; these belonged to an older age group and had longer medical histories.

Dietary investigation. The diet of each of the children suffering from liver disease was inquired into during this investigation, but the food intake of ten children was studied in more detail and compared with that of five healthy controls. Their ages varied from 9 months to 8 years, the majority being between 9 months and 3 years. Eight were male. The dietary measurements were made in the children's homes by 